\title{
Small airways dysfunction: the link between allergic rhinitis and allergic asthma
}

\author{
Amaryllis Haccuria ${ }^{1}$, Alain Van Muylem ${ }^{1}$, Andrei Malinovschi ${ }^{2}$, Vi Doan ${ }^{1}$ and \\ Alain Michils ${ }^{1}$
}

Affiliations: ${ }^{1}$ Chest Dept, Erasme University Hospital, Université Libre de Bruxelles, Brussels, Belgium. ${ }^{2}$ Dept of Medical Sciences: Clinical Physiology, Uppsala University, Uppsala, Sweden.

Correspondence: Alain Van Muylem, Chest Dept, CUB Erasme, Université Libre de Bruxelles, 808 Route de Lennik, 1070 Brussels, Belgium. E-mail: avmuylemaulb.ac.be

\section{@ERSpublications}

Abnormal airway reactivity and NO production are detected in peripheral airways of patients with allergic rhinitis http://ow.ly/hSwc30hdOm2

Cite this article as: Haccuria A, Van Muylem A, Malinovschi A, et al. Small airways dysfunction: the link between allergic rhinitis and allergic asthma. Eur Respir J 2018; 51: 1701749 [https://doi.org/10.1183/ 13993003.01749-2017].

ABSTRACT Abnormal airway reactivity and overproduction of nitric oxide (NO) occurring in small airways have been found in asthma. If the "one airway, one disease" concept is consistent, such dysfunctions should also be detected in the peripheral airways of patients suffering from allergic rhinitis.

We investigated whether peripheral airway reactivity and NO overproduction could be documented in distal airways in patients with allergic rhinitis. Exhaled NO fraction $\left(F_{\mathrm{eNO}}\right)$ and the slope (S) of phase III of the single-breath washout test (SBWT) of helium (He) and sulfur hexafluoride $\left(\mathrm{SF}_{6}\right)$ were measured in 31 patients with allergic asthma, 23 allergic rhinitis patients and 24 controls, before and after sputum induction. SBWT is sensitive to airway calibre change occurring in the lung periphery.

The FeNO decrease was more significant in asthma and rhinitis than in controls $(-55.1 \%$ and $-50.0 \%$,

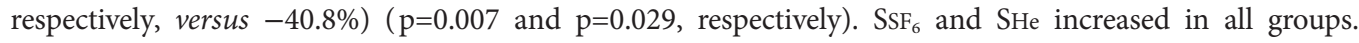
Change in $\mathrm{SHe}(\Delta \mathrm{SHe})>\Delta \mathrm{SSF}_{6}$ was observed in rhinitis $(\mathrm{p}=0.004)$ and asthma $(\mathrm{p}<0.001)$, whereas $\Delta \mathrm{SsF}_{6}=$ $\Delta \mathrm{SHe}$ in controls $(\mathrm{p}=0.431)$.

This study provides evidence of peripheral airway dysfunction in patients with allergic rhinitis quite similar to that described in asthma. Furthermore, a large proportion of the increased NO production reported in allergic rhinitis appears to originate in the peripheral airways.

Received: Aug 252017 | Accepted after revision: Dec 072017

Support statement: This study was supported by Fonds Erasme (Convention André Arouète). Funding information for this article has been deposited with the Crossref Funder Registry.

Conflict of interest: Disclosures can be found alongside this article at erj.ersjournals.com

Copyright @ERS 2018 


\section{Introduction}

The upper and lower airways are currently considered to be a morphological and functional entity, and there is robust epidemiological, pathophysiological and clinical evidence supporting an integrated view of rhinitis and asthma, especially in allergic subjects $[1,2]$. While sharing a common genetic background, these two closely related diseases have common physiological and inflammatory mechanisms featuring an airway hypersensitivity syndrome [3]. In fact, both conditions share the same type 2 T-helper cell (Th2) inflammatory process, as attested by increased blood [4] and sputum eosinophil [5] counts, and exhaled nitric oxide fraction $(F \mathrm{eNO}$ ) levels $[6,7]$. In addition, nonspecific bronchial hyperresponsiveness, which is a characteristic feature of asthma [8], was shown to be frequently documented in patients suffering from allergic rhinitis without asthma symptoms $[9,10]$. Taken together, this led to the advent of the so-called "one airway, one disease" or the "united airways" concept [11].

Conversely, there is recent evidence showing that small airway disease contributes significantly to asthma pathophysiology [12]. In fact, both the inflammatory process and airway dysfunction involve large and small airways in asthma $[13,14]$. In this context, we have shown, using indirect airway challenge with AMP that patients suffering from asthma display bronchial hyperresponsiveness involving the peripheral airways, as abnormal reactivity was detectable up to the respiratory bronchioles [15]. Peripheral airway reactivity was assessed by the inert gas washout technique with helium $(\mathrm{He})$ and sulphur hexafluoride $\left(\mathrm{SF}_{6}\right)$. This technique was shown to be sensitive to changes in airway calibre in the lung periphery [16].

Bronchial challenge results in a decrease of exhaled nitric oxide (NO) in asthma, regardless of the type of provocation. Furthermore, agents that lead to a constriction further down in the airway tree, such as AMP compared to methacholine, and allergens result in a larger decrease of FeNO in subjects with asthma [17, 18]. This is probably because a substantial amount of the NO overproduction occurring in allergic asthma comes from small, pre-acinar airways [17].

If the "one airway, one disease" concept is consistent, it may be hypothesised that the peripheral airways of patients suffering from allergic rhinitis but without asthma could be additionally abnormal in terms of airway reactivity, and involved in NO overproduction. Therefore, we investigated whether peripheral airway hyperresponsiveness, assessed by the inert gas washout technique, and FeNO changes in relation to indirect airway challenge, could be found in subjects with allergic rhinitis, but without asthma.

We used the induced sputum procedure, as it offers the advantage of being equivalent to the indirect challenge [19] used in our previous article [15] (i.e. AMP) and provides information on the inflammatory status of the airway [20].

\section{Material and methods \\ Subjects}

Patients suffering from allergic rhinitis or intermittent or moderate-to-mild persistent allergic asthma, as well as healthy volunteers were recruited from the outpatient asthma clinic at CUB-Erasme University Hospital (Brussels, Belgium). Asthma was defined according to the standard criteria [8]. At the time of inclusion, patients were nonsmokers, with no recent history of upper airway infection. Asthma treatment was halted for 1 week with the exception of on-demand inhaled short-acting $\beta_{2}$-agonists, which were withheld for $\geqslant 6 \mathrm{~h}$ before the induced sputum procedure. Similarly, treatment for allergic rhinitis was stopped 1 week before the procedure. Atopic status was evaluated using skin-prick testing towards common inhalant allergens.

Healthy volunteers were recruited among subjects with no symptoms of rhinitis or asthma who exhibited normal lung function and tested negative to common aeroallergens.

The study was approved by the local ethics committee in (CUB Erasme University Hospital). All patients involved signed consent forms.

\section{Study design}

The study was designed as a prospective open study and performed in the chest department of the Erasme University Hospital.

FeNO levels, spirometry parameters and ventilation distribution using single-breath washout tests were measured sequentially during and after sputum induction.

FeNO

FeNO was measured prior to any forced expiratory manoeuvres using a daily calibrated LR 2000 chemiluminescence analyser (Logan Research, Rochester, UK), with the online measurement of a single exhalation at flow rate of $50 \mathrm{~mL} \cdot \mathrm{s}^{-1}$ (American Thoracic Society/European Respiratory Society standard) [21]. 
Exhaled NO levels were read at the plateau corresponding to $70-80 \%$ of the carbon dioxide $\left(\mathrm{CO}_{2}\right)$ curve. Absolute FeNO values were expressed in ppb and FeNO changes as a percentage of the baseline value $(\Delta \%)$.

\section{Lung function}

Lung function was measured using a Zan 300 spirometer (Zan, Oberthulba, Germany) following standard guidelines [22]. Forced expiratory volume in $1 \mathrm{~s}$ (FEV1), forced vital capacity and forced expiratory flow at $75 \%$ of maximal expired volume were expressed as a percentage of the predicted value, while changes were expressed as a percentage of the baseline value $(\Delta \%)$.

\section{Ventilation distribution tests with inert gases}

Ventilation distribution was assessed via single-breath washout tests. Subjects were connected to a double bag-in-box system through a nonrebreathing valve with a $20 \mathrm{~mL}$ instrumental dead space. They inhaled a gas mixture containing two inert gases: $5 \% \mathrm{He}$ and $5 \% \mathrm{SF}_{6}$ in oxygen $\left(\mathrm{O}_{2}\right)$, from functional residual capacity (FRC) to $1 \mathrm{~L}$ more than FRC, and then expired at a constant flow of $\sim 0.40 \mathrm{~L} \cdot \mathrm{s}^{-1}$ to residual volume. This test, based on $1 \mathrm{~L}$ inspired from FRC, was shown to better reflect distal ventilation than the standard vital capacity test [23]. A shorter inspiratory time allows peripheral diffusion-driven heterogeneities to be preserved, while being less influenced by larger scale heterogeneities [24]. The gas mixture (containing $90 \% \mathrm{O}_{2}$ ) is routinely used to assess nitrogen dilution in other contexts. In the present study, we only focused on $\mathrm{He}$ and $\mathrm{SF}_{6}$. These are so-called nonresident gases, differing only in their diffusive properties, thereby allowing for a fair comparison between both.

During expiration, $\mathrm{He}$ and $\mathrm{SF}_{6}$ concentrations were recorded as a function of expired volume using a quadrupole mass spectrometer (LR6000; Logan-Sinclair, Rochester, UK), which was calibrated immediately prior to each set of measurements (calibration cylinders $6 \% \mathrm{CO}_{2}, 15 \% \mathrm{O}_{2}$ and $79 \%$ nitrogen, as well as $5 \%$ $\mathrm{He}, 5 \% \mathrm{SF}_{6}$ and $90 \% \mathrm{O}_{2}$; Messer Belgium, Zwijdrecht, Belgium). The delay between the volume and concentration signals due to the capillary transit time was assessed when the subject re-inhaled the $5 \%$ $\mathrm{He}, 5 \% \mathrm{SF}_{6}$ and $90 \% \mathrm{O}_{2}$ mixture after reaching residual volume. The signals were consequently instantaneously synchronised.

Slopes (S) for each gas $\left(\mathrm{SHe}, \mathrm{SSF}_{6}\right)$ were computed using a computerised linear regression model (concentration versus expired volume) set at between $35 \%$ and $80 \%$ of the expired volume. If deemed appropriate, the regression limits could be set manually in order to avoid dead space or closing volume. $\mathrm{He}$ and $\mathrm{SF}_{6}$ slopes were expressed in $\% \cdot \mathrm{L}^{-1}$. In addition, these slopes were multiplied by -15.6 , allowing for a comparison with the values of nitrogen slope reported in the literature [15]. The test was performed in triplicate, with a variation coefficient $<10 \%$.

\section{Sputum induction and processing}

Sputum was induced by inhaling $50 \mathrm{~mL}$ hypertonic saline (5\% sodium chloride) from an ultrasonic nebuliser (MONSUN U910; Maquet, Rastatt, Germany), which delivers particles with an aerodynamic mass median diameter of $5 \mu \mathrm{m}$ at an output of $3 \mathrm{~mL} \cdot \mathrm{min}^{-1}: 5 \mu \mathrm{m}$ ). Each subject inhaled the aerosol for four consecutive periods of $5 \mathrm{~min}$, for a total duration of $20 \mathrm{~min}$.

The entire amount of resulting sputum was collected in a plastic container, weighed and homogenised by adding three volumes of PBS, vortexed for $30 \mathrm{~s}$ and centrifuged at $800 \times g$ for $10 \mathrm{~min}$ at $4^{\circ} \mathrm{C}$. Supernatant was separated from cell pellet. We then added dithiotreitol to the cells, which were agitated for $20 \mathrm{~min}$. These cells were again washed with PBS and resuspended in $1 \mathrm{~mL}$. Squamous cell counts, total cell counts and cell viability, checked by trypan blue exclusion, were performed using a manual haemocytometer. When squamous cells were $>70 \%$, the sample was deemed inappropriate. The differential cell count was performed on cytospins stained with Diff-Quick after counting 400 cells [25].

\section{Statistical analysis}

FeNO was log-transformed prior to statistical analyses. Differences between the three groups and differences before and after sputum induction (and their interaction) were assessed using a linear mixed model with groups and sputum induction as fixed effects. We considered the pre-induction value as a random effect (random intercept model). Other comparisons were made using one-way ANOVA (age and baseline $\mathrm{FEV}_{1} \%$ pred), Chi-squared test for male/female proportions and a Kruskal-Wallis test followed by a Dunn test for eosinophil percentage in sputum. The R software [26] was used. Statistical significance was defined as a p-value of $<0.05$ (two-tailed). 
TABLE 1 Population characteristics

\begin{tabular}{lcccccc} 
& Controls & Rhinitis & Asthma & $\begin{array}{c}\text { p-value controls- } \\
\text { rhinitis }\end{array}$ & $\begin{array}{c}\text { p-value controls- } \\
\text { asthma }\end{array}$ & $\begin{array}{c}\text { p-value rhinitis- } \\
\text { asthma }\end{array}$ \\
\hline Subjects $\mathbf{n}$ & 24 & 23 & 31 & & & \\
Age years & $27 \pm 5$ & $35 \pm 11$ & $36 \pm 10$ & 0.003 & 0.002 & 0.780 \\
Male/female & $5 / 19$ & $15 / 8$ & $15 / 16$ & 0.002 & 0.035 & 0.218 \\
Atopy & 0 & 23 & 31 & & & \\
\hline
\end{tabular}

Data are presented as $\mathrm{n}$ or mean $\pm \mathrm{SD}$, unless otherwise stated.

\section{Results}

\section{Patients}

31 allergic asthma patients, 23 patients with allergic rhinitis and 24 healthy volunteers were enrolled in the study. Patient characteristics are summarised in table 1. Baseline values of FeNO and lung function parameters are presented in table 2 .

\section{Effect of sputum induction}

Pre-post induction individual changes of $F$ eNO and functional indices are presented in figure 1.

All indices changed significantly except for FEV1 in the control group.

Figure 2 shows the changes as a percentage of baseline and the statistical significances of the differences between groups.

\section{Standard pulmonary function}

For FEV1, the mean decrease in the asthma group $(-17.5 \%)$ is significantly greater than that observed in the two other groups $(\mathrm{p}<0.001)$, which appear to be similar $(-4.2 \%$ and $-4.8 \%$ in healthy controls and rhinitis patients, respectively; $\mathrm{p}=0.868)$.

\section{FenO}

Considering $F$ eNO, the mean decrease in the asthma group (-55.1\%) was greater than that observed in the control $(-40.8 \%, \mathrm{p}=0.007)$. Rhinitis group decrease $(-50.0 \%)$ is closer to asthma group decrease $(\mathrm{p}=0.447)$ and greater than control group $(\mathrm{p}=0.029)$.

\section{Ventilation distribution indices}

For $\mathrm{SHe}$, the mean increase in the asthma group $(+242.9 \%)$ was significantly greater than the control group $(+74.1 \%, \mathrm{p}=0.002)$; the rhinitis group exhibited an intermediate increase $(+127.2)$ between the control group increase $(\mathrm{p}=0.046)$ and the asthma group increase $(\mathrm{p}=0.053)$. For $\mathrm{SsF}_{6}$, all increases were similar and significant: $+94.6 \%,+64.7 \%$ and $+141.4 \%$ for the control, rhinitis and asthma groups, respectively $(\mathrm{p}>0.05)$.

Moreover, $\mathrm{SHe}$ and $\mathrm{SSF}_{6}$ increased to a similar extent in the control group $(+74.1 \%$ versus $+94.6 \%$; $\mathrm{p}=0.431)$, whereas $\mathrm{SHe}$ increased significantly more than $\mathrm{SSF}_{6}$ in both the rhinitis $(+127.2 \%$ versus $64.7 \%$; $\mathrm{p}=0.004)$ and the asthma $(+242.9 \%$ versus $+141.4 \%$; $\mathrm{p}<0.001)$ groups.

TABLE 2 Pre-induction values of exhaled nitric oxide fraction ( $F$ eNO $)$ and of functional indices

\begin{tabular}{lcccccc} 
& Controls & Rhinitis & Asthma & $\begin{array}{c}\text { p-value controls- } \\
\text { rhinitis }\end{array}$ & $\begin{array}{c}\text { p-value controls- } \\
\text { asthma }\end{array}$ & $\begin{array}{c}\text { p-value rhinitis- } \\
\text { asthma }\end{array}$ \\
\hline FEV $1 \%$ pred & $104.9 \pm 11.4$ & $103.7 \pm 13.2$ & $98.9 \pm 12.1$ & 0.804 & 0.153 \\
FeNo ppb & $9.9(6.1-16)$ & $36.2(19.3-68.1)$ & $43.2(19.4-96.5)$ & $<0.001$ & $<0.001$ & 0.190 \\
SHe \%.L & $1.28 \pm 0.54$ & $1.34 \pm 0.62$ & $2.29 \pm 1.96$ & 0.774 & 0.027 & 0.359 \\
SsF $_{6} \% \cdot \mathbf{L}^{-1}$ & $1.84 \pm 0.94$ & $2.21 \pm 0.96$ & $2.83 \pm 1.05$ & 0.108 & 0.004 & 0.058 \\
\hline
\end{tabular}

Data are presented as mean $\pm S D$ or geometric mean (geometric interval) (geometric mean is antilog(mean) and geometric interval is (antilog (mean-SD) - antilog(mean+SD)) of the log-transformed $\left.F_{\mathrm{eNO}}\right)$, unless otherwise stated. FEV1: forced expiratory volume in $1 \mathrm{~s}$; S: slope; He: helium; $\mathrm{SF}_{6}$ : sulfur hexafluoride. 

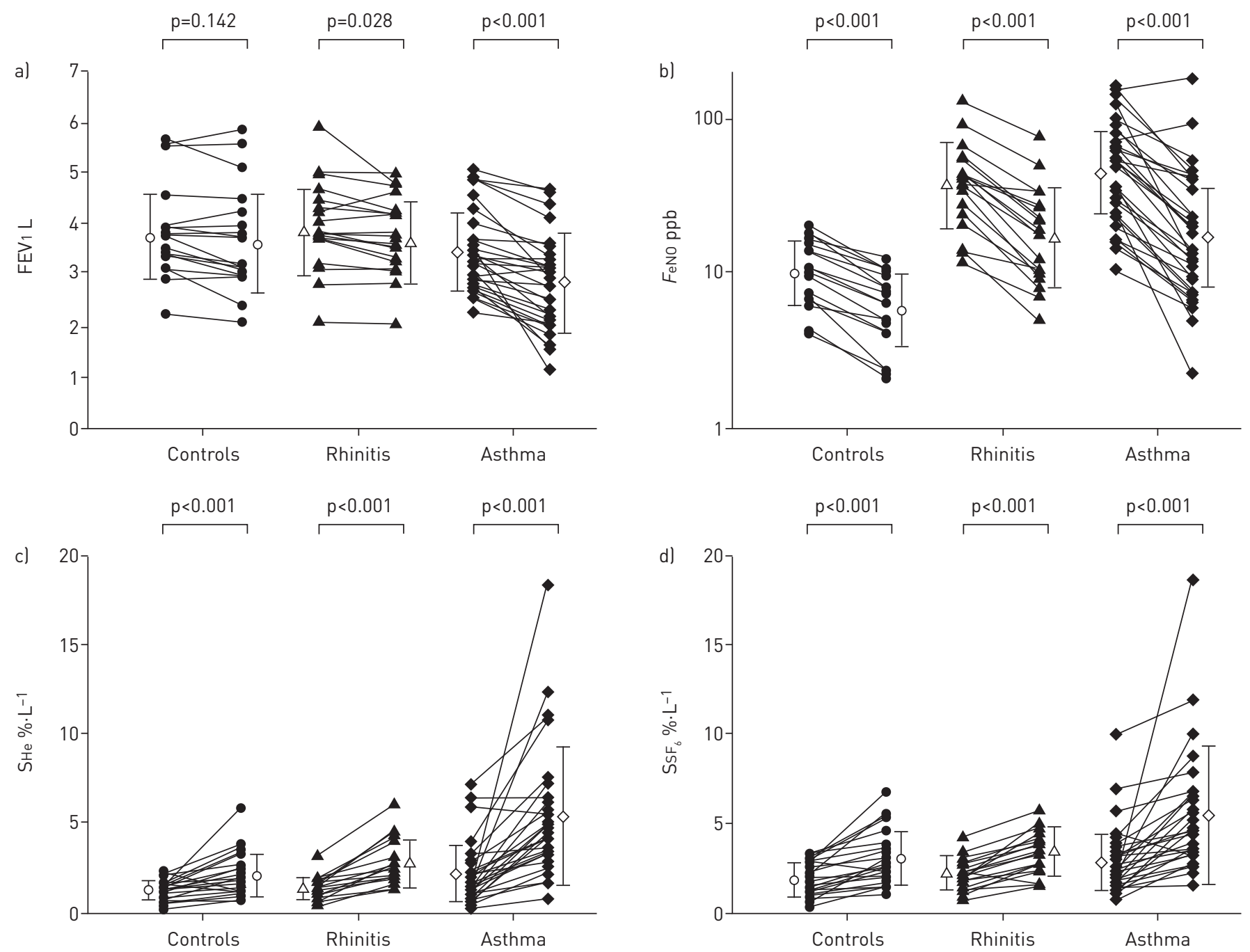

FIGURE 1 Pre-/post-induction individual changes for al forced expiratory volume in $1 \mathrm{~s}$ (FEV1), b) exhaled nitric oxide fraction (FeNo), c) slope for helium ( $\mathrm{SHe}$ ) and d) slope for sulfur hexafluoride $\left(\mathrm{SSF}_{6}\right)$ in controls, rhinitis and asthma groups. Open symbols represent the corresponding means \pm SD.

\section{Sputum production and quality}

$42 \%$ (10 out of 24 ) of healthy controls, $100 \%$ (23 out of 23 ) of allergic rhinitis patients and $90.6 \%$ (28 out of 31) of asthma patients produced sputum.

Sputa contaminated with $>70 \%$ squamous cells and/or revealing $<60 \%$ cell viability were considered unsuitable for further cell count [25]. 91\% (9 out of 10) of healthy controls, $60 \%$ (14 out of 23) of allergic rhinitis patients, and $65.5 \%$ (18 out of 28 ) of asthma patients produced good quality sputum. The median (range) of eosinophil percentages were $0(0-09) \%, 0.4(0-75.6) \%$ and $6.9(0-63) \%$ for control subjects, rhinitis patients and asthma patients, respectively. Asthma patients differed from controls $(\mathrm{p}<0.001)$ and rhinitis patients ( $\mathrm{p}=0.003$ ); rhinitis patients exhibited a tendency to have higher percentages of eosinophils than controls.

\section{Discussion}

This study provides evidence that allergic rhinitis is associated with peripheral airway dysfunction. First, patients with allergic rhinitis display an abnormal peripheral airway responsiveness that is quite similar to that documented in asthma [15]. Furthermore, the type-2 airway inflammatory process, associated with increased FeNO reported in allergic rhinitis, finds its origin in the same peripheral airways as in asthma [17]. This clearly indicates that the so-called "one airway, one disease" concept linking allergic asthma and allergic rhinitis applies to peripheral airways.

There is evidence that allergic asthma and allergic rhinitis are closely related conditions, sharing common physiological and inflammatory pathways [1]. Over the past few years, it has been demonstrated that small 

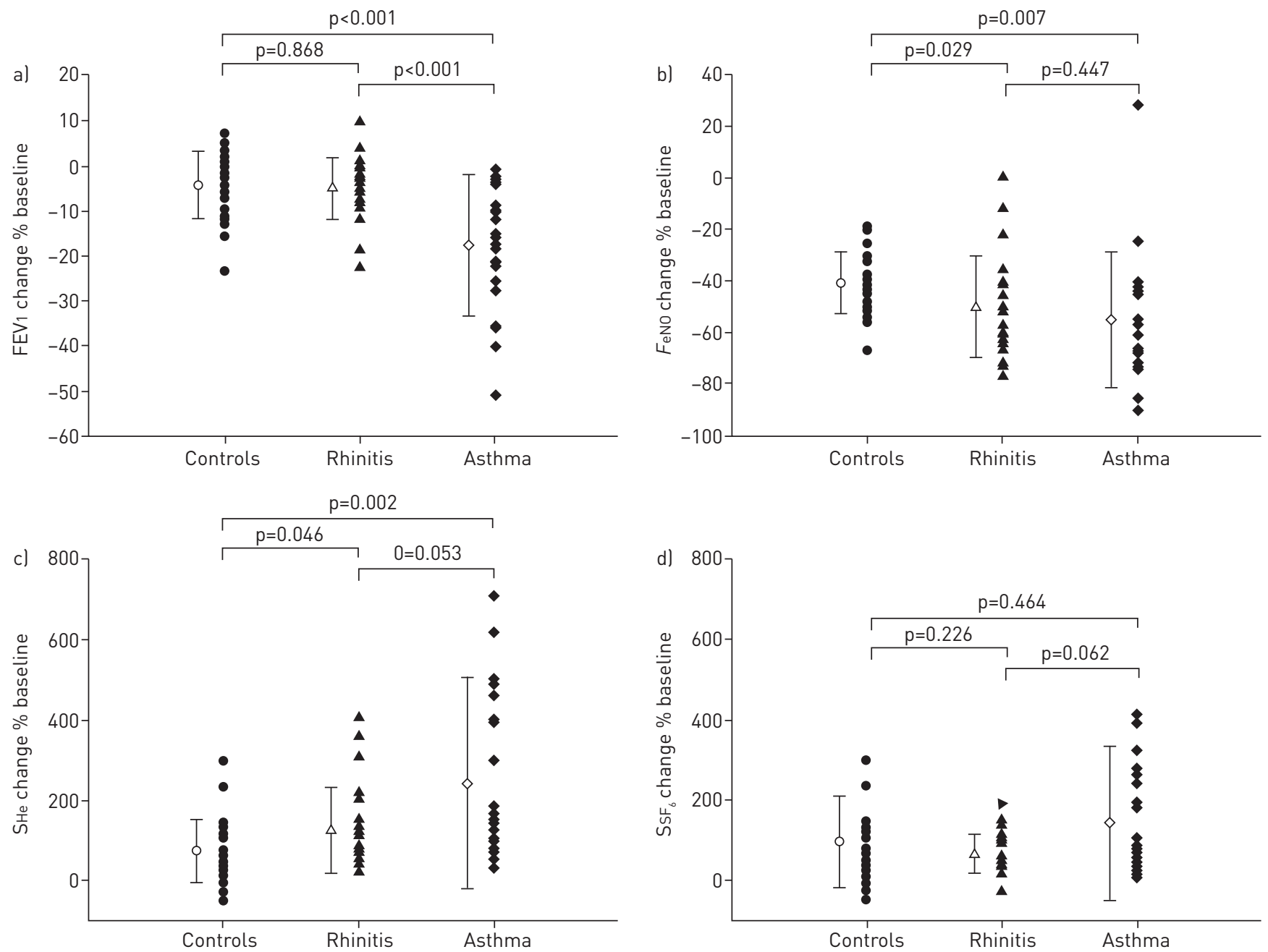

FIGURE 2 Pre-/post-induction individual changes expressed as a percentage of baseline for a) forced expiratory volume in $1 \mathrm{~s}$ (FEV 1 ), b) exhaled nitric oxide fraction $\left.\left(F_{\mathrm{eNO}}\right), \mathrm{c}\right)$ slope for helium $\left(\mathrm{SHe}_{\mathrm{e}}\right)$ and $\mathrm{d}$ ) slope for sulfur hexafluoride $\left(\mathrm{SSF}_{6}\right)$ in controls, rhinitis and asthma groups. Open symbols represent the corresponding means \pm SD.

airways dysfunction contributes significantly to the pathophysiology of asthma [12]. To this end, we have documented an abnormal airway reactivity and significant NO production, marking a Th2-type inflammatory process, located in the small and peripheral airways of patients suffering from asthma [15, 17]. Here, we provide evidence that the peripheral airways of patients suffering from allergic rhinitis without asthma exhibit similar abnormalities.

In order to evaluate proximal and peripheral airway reactivity in patients with allergic rhinitis, we measured FEV1 and ventilation distribution with SBWT using the inert gases $\mathrm{He}$ and $\mathrm{SF}_{6}$, before and after sputum induction. The latter procedure is considered to be similar to an indirect airway challenge with hypertonic saline, and offers the opportunity to investigate airway inflammation $[19,20]$. In fact, SBWT was previously shown to be sensitive to change in airway calibre occurring in lung periphery during airway challenge in asthma patients [15]. In short, this means that when a nonresident inert gas is inhaled and exhaled, after exhalation of dead space volume, the expired concentration reaches a plateau known as phase III, the slope of which reflects the ventilation heterogeneities generated during inspiration. When two nonresident inert gases that differ only in their diffusive properties, such as $\mathrm{He}$ and $\mathrm{SF}_{6}$, are simultaneously inhaled and expired by a normal subject, they produce slopes of different magnitudes, evidencing the role of molecular diffusion in the genesis of the phase III slope. Theoretic considerations, together with anatomic knowledge about bronchial tree dimensions and peripheral asymmetry [27, 28], indicate that this slope is particularly sensitive to airway alterations, which occur where convention transport, dramatically decreasing in peripheral airways, is balanced by diffusion transport, sometimes coined as the "diffusion front". Given that $\mathrm{He}$ and $\mathrm{SF}_{6}$ have the same convection velocity at any axial point and differ only in terms of their diffusive properties, their respective diffusion fronts have different 
a)

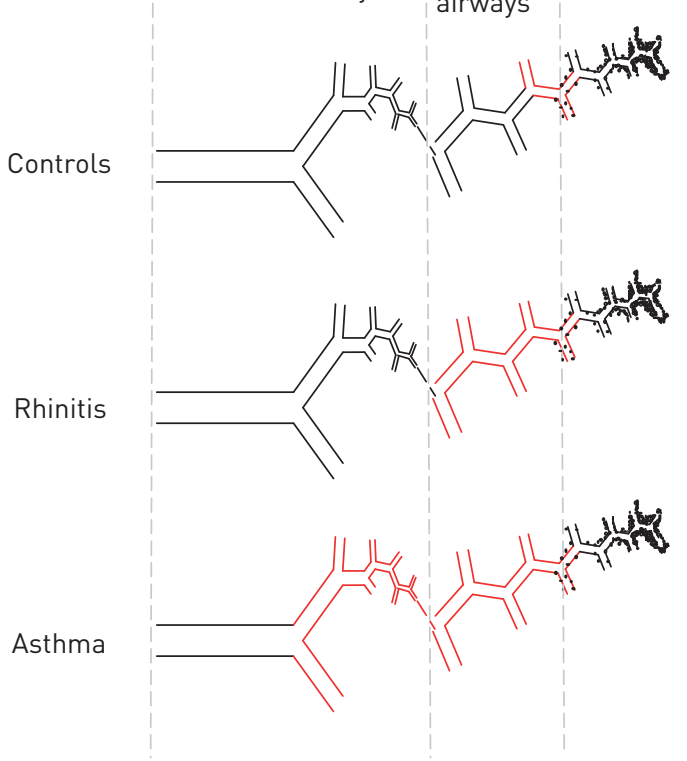

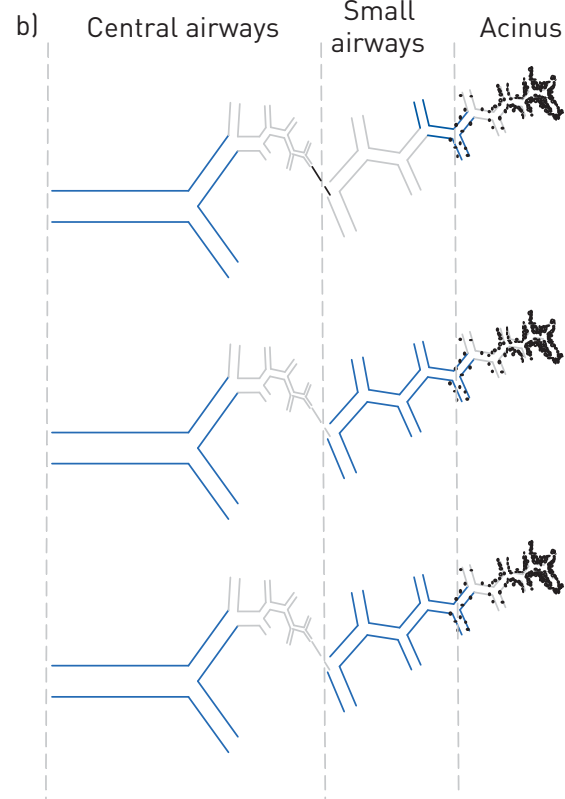

FIGURE 3 a) Schematic representation of the sites of the airway response (in red) to an indirect challenge in healthy controls, patients with allergic rhinitis and asthma patients; b) schematic representation (in blue) of the sites of nitric oxide production in control subjects (based on [32, 35]), asthma (based on [17]) and rhinitis patients.

locations. Therefore, the slopes of these gases reflect alterations at different levels of the bronchial tree that may be estimated by knowing diffusion coefficients and axial velocity: the terminal and respiratory bronchioles for $\mathrm{He}$ and the alveolar ducts for $\mathrm{SF}_{6}$ [27], the "weaker" diffusion of the latter only being able to balance a smaller, hence more peripheral velocity. It has been demonstrated that proximal [15] and distal [29] structural alterations have little effect on diffusion fronts locations, allowing for fair comparisons of post-challenge values with baseline values. When airway alterations are induced, the relative increases $(\Delta)$ in $\mathrm{SHe}_{\mathrm{H}}$ and $\mathrm{SsF}_{6}$ indicate the site where the alterations occur: $\Delta \mathrm{SHe}>\Delta \mathrm{SsF}_{6}$ probably reflects alterations at the level of the terminal and respiratory bronchioles and $\Delta \mathrm{SsF}_{6}>\Delta \mathrm{SHe}_{\mathrm{H}}$ shows alterations inside the acinus, whereas $\Delta \mathrm{SHe}=\Delta \mathrm{SSF}_{6}$ reflects peripheral alteration occurring prior to or beyond the diffusion front zones of both gases [30, 31].

Taking our combined findings into account, including changes in FEV1, three varying patterns of airway response to sputum induction could be identified in our three populations, as shown in figure 3 . First, in the asthma group, sputum induction elicited a significant FEV1 fall in a large proportion of patients, as expected with a procedure considered to be similar to an indirect bronchial challenge with hypertonic

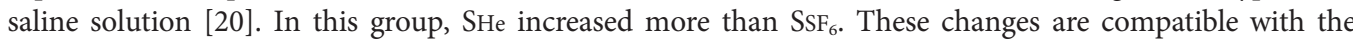
constriction of proximal and peripheral airways up to the respiratory bronchioles induced by the procedure, which is exactly the same as when using AMP to perform airway challenge in asthma patients [15]. Second, in most patients suffering from allergic rhinitis, FEV1 fall was modest after sputum induction, while $\mathrm{SHe}$ increased more than $\mathrm{SSF}_{6}$, indicating a peripheral ventilation impairment up to the respiratory bronchioles in the absence of a significant proximal response. In most healthy volunteers, FEV 1 was not significantly influenced by sputum induction; slopes of $\mathrm{He}$ and $\mathrm{SF}_{6}$ increased similarly after the procedure; and FeNO levels decreased. According to theoretical models and heliox experiments [17, 32, 33], this is compatible with a very peripheral alteration. Combined, our data indicate that the peripheral airway responsiveness displayed by patients with allergic rhinitis appears similar to that exhibited by asthma patients. This suggests a common pattern of peripheral airway responsiveness in patients suffering from asthma and allergic rhinitis that was not highlighted in the previous few studies on this subject [34, 35]. In fact, a higher degree of peripheral airway responsiveness was documented in both conditions when changes in reactance at $5 \mathrm{~Hz}$ or area under reactance, measured by impulse oscillometry, were used to assess peripheral airways responsiveness to methacholine in children [34]. However, in adults, only subjects with allergic rhinitis with proven bronchial hyperresponsiveness, by FEV1 decrease of $\geqslant 20 \%$, but not subjects with allergic rhinitis without bronchial hyperresponsiveness showed signs of peripheral airways involvement, proven by impulse oscillometry [35]. It could be argued that this technique might be less sensitive than SBWT used in our study. Taken together, our data fit well with the "one airway, one 
disease" concept described in asthma and rhinitis: allergic rhinitis or asthma patients display a similar pattern of peripheral airway responsiveness that is distinct from that observed in nonatopic control subjects. The mechanism behind the highly localised peripheral airway reactivity reported in healthy controls for the first time as far as we are aware, remains unknown. The distinctive feature between allergic rhinitis and allergic asthma, in terms of airway reactivity, appears to be proximal airway responsiveness (i.e. $\mathrm{FEV} 1$ decrease) restricted to allergic asthma.

Finally, as regards airway reactivity, the data summarised in figure 3a suggest a continuous progression from a peri-acinar involvement only, to a peri-acinar up to terminal bronchioles involvement or a peri-acinar up to proximal airways involvement, in healthy controls on patients with allergic rhinitis and allergic asthmatics, respectively.

As expected, FeNO levels were elevated to a similar extent in both asthma and allergic rhinitis. In fact, there is evidence of common Th2 pathways in allergic rhinitis and allergic asthma as reflected by increased blood and sputum eosinophil counts and increased FeNO levels [4-7] documented in both conditions. In this study, we confirmed to some extent an eosinophilic Th2 type inflammatory process occurring within the airways of patients with allergic rhinitis. While sputum eosinophil count was far below that observed in patients with allergic asthma, it was significantly higher than that documented in healthy controls. In addition, we were able to show, for the first time as far as we are aware, that in allergic rhinitis the NO overproduction site is located in peripheral airways, exactly as indicated in asthma [17]. In fact, over the past decade, experiments and simulations have found that a large amount of NO production is concentrated in pre-acinar small airways in healthy subjects [32, 33] as well as in asthma patients [17]. Thus, FeNO may be considered as reflecting NO production in peripheral airways rather than in central ones. Provocation challenges affecting this peripheral zone [15] reduce airway calibre, and consequently the epithelium-airway lumen interface through which NO diffuses [36]. Therefore, for an unchanged epithelial NO production, a reduced amount of NO reaches the airway lumen, decreasing FeNO especially as constrictions arise where NO production is elevated. The significant FeNO reduction observed after sputum induction in patients with allergic rhinitis, together with the ventilation impairment affecting $\mathrm{SHe}$ slopes much more, in the absence of concomitant FEV1 change, indicate that a significant amount of NO is produced in terminal and respiratory bronchioles in this condition, as it does in asthma [17] (figure 3b). These findings ultimately suggest that an active Th2 type inflammatory process occurs in the peripheral airways of patients suffering from allergic rhinitis without asthma.

To conclude, this study provides evidence of peripheral airway dysfunction in patients with allergic rhinitis. First, a common pattern of peripheral airway responsiveness involving terminal and respiratory bronchioles and distinct from that of healthy controls is documented in patients with allergic asthma and allergic rhinitis. Incidentally, it is likely that the involvement of both proximal and peripheral airway distinguishes airway hyperresponsiveness in allergic asthma from airway responsiveness in allergic rhinitis. Second, a large proportion of the increased NO production reported in allergic rhinitis and marking an active Th2 type inflammatory process appears to originate in lower peripheral airways, i.e. terminal and respiratory bronchioles. Overall, the overwhelming message from this study is that the "one airway, one disease" concept linking allergic asthma and allergic rhinitis applies to peripheral airways as well.

\section{Acknowledgements}

The authors would like to thank Tom O'Connell (OCPR, Brussels, Belgium) for proofreading the manuscript.

\section{References}

1 Togias A. Rhinitis and asthma: evidence for respiratory system integration. J Allergy Clin Immunol 2003; 111: 1171-1183.

2 Bousquet J, Van Cauwenberge P, Khaltaev N, et al. Allergic rhinitis and its impact on asthma. J Allergy Clin Immunol 2001; 108: Suppl., S147-S334.

3 Giavina-Bianchi P, Aun MV, Takejima P, et al. United airway disease: current perspectives. J Asthma Allergy 2016; 9: 93-100.

4 Jung YG, Kim KH, Kim HY, et al. Predictive capabilities of serum eosinophil cationic protein, percentage of eosinophils and total immunoglobulin $\mathrm{E}$ in allergic rhinitis without bronchial asthma. J Int Med Res 2011; 39: 2209-2216.

5 Polosa R. Bronchial hyperresponsiveness and airway inflammatory markers in nonasthmatics with allergic rhinitis. Eur Respir J 2000; 16: 793.

6 Linhares D, Jacinto T, Pereira AM, et al. Effects of atopy and rhinitis on exhaled nitric oxide values - a systematic review. Clin Transl Allergy 2011; 1: 8.

7 Kharitonov SA, Yates D, Robbins RA, et al. Increased nitric oxide in exhaled air of asthmatic patients. Lancet 1994; 343: 133-135.

8 Global Initiative for Asthma. 2015. www.ginaasthma.com. Date last accessed: November 2015.

9 Ramsdale EH, Morris MM, Roberts RS, et al. Asymptomatic bronchial hyperresponsiveness in rhinitis. $J$ Allergy Clin Immunol 1985; 75: 573-577. 
10 Saranz RJ, Lozano A, Lozano NA, et al. Subclinical lower airways correlates of chronic allergic and non-allergic rhinitis. Clin Exp Allergy 2017; 47: 988-997.

11 Passalacqua G, Ciprandi G, Canonica GW. The nose-lung interaction in allergic rhinitis and asthma: united airways disease. Curr Opin Allergy Clin Immunol 2001; 1: 7-13.

12 Bonini M, Usmani OS. The role of the small airways in the pathophysiology of asthma and chronic obstructive pulmonary disease. Ther Adv Respir Dis 2015; 9: 281-293.

13 Hamid Q, Song Y, Kotsimbos TC, et al. Inflammation of small airways in asthma. J Allergy Clin Immunol 1997; 100: 44-51.

14 Carroll N, Cooke C, James A. The distribution of eosinophils and lymphocytes in the large and small airways of asthmatics. Eur Respir J 1997; 10: 292-300.

15 Michils A, Elkrim Y, Haccuria A, et al. Adenosine 5'-monophosphate challenge elicits a more peripheral airway response than methacholine challenge. J Appl Physiol 2011; 110: 1241-1247.

16 Gustafsson PM, Ljungberg HK, Kjellman B. Peripheral airway involvement in asthma assessed by single-breath SF6 and He washout. Eur Respir J 2003; 21: 1033-1039.

17 Van Muylem A, Kerckx Y, Michils A. Axial distribution of nitric oxide airway production in asthma patients. Respir Physiol Neurobiol 2013; 185: 313-318.

18 Haccuria A, Michils A, Michiels S, et al. Exhaled nitric oxide: a biomarker integrating both lung function and airway inflammation changes. J Allergy Clin Immunol 2014; 134: 554-559.

19 Joos GF, O'Connor B, Anderson SD, et al. Indirect airway challenges. Eur Respir J 2003; 21: 1050-1068.

20 Pavord ID, Sterk PJ, Hargreave FE, et al. Clinical applications of assessment of airway inflammation using induced sputum. Eur Respir J 2002; 37: Suppl. 40s-43s.

21 Dweik RA, Boggs PB, Erzurum SC, et al. An official ATS clinical practice guideline: interpretation of exhaled nitric oxide levels (FeNO) for clinical applications. Am J Respir Crit Care Med 2011; 184: 602-615.

22 Quanjer PH, Tammeling GJ, Cotes JE, et al. Lung volumes and forced ventilatory flows. Eur Respir J 1993; 6: Suppl. 16, 5-40.

23 Paiva M, Verbanck S, van Muylem A. Diffusion-dependent contribution to the slope of the alveolar plateau. Respir Physiol 1988; 72: 257-270.

24 Paiva M, van Muylem A, Ravez P, et al. Inspired volume dependence of the slope of the alveolar plateau. Respir Physiol 1984; 56: 309-325.

25 Efthimiadis A, Spanevello A, Hamid Q, et al. Methods of sputum processing for cell counts, immunocytochemistry and in situ hybridisation. Eur Respir J 2002; 20: Suppl. 37, 19s-23s.

26 R Core Team. R: a Language and Environment for Statistical Computing. Vienna, R Foundation for Statistical Computing.

27 Paiva M, Engel LA. Theoretical studies of gas mixing and ventilation distribution in the lung. Physiol Rev 1987; 67: 750-796.

28 Haefeli-Bleuer B, Weibel ER. Morphometry of the human pulmonary acinus. Anat Rec 1988; 220: 401-414.

29 Dutrieue B, Vanholsbeeck F, Verbanck S, et al. A human acinar structure for simulation of realistic alveolar plateau slopes. J Appl Physiol 2000; 89: 1859-1867.

30 Estenne M, Van Muylem A, Knoop C, et al. Detection of obliterative bronchiolitis after lung transplantation by indexes of ventilation distribution. Am J Respir Crit Care Med 2000; 162: 1047-1051.

31 Van Muylem A, De Vuyst P, Yernault JC, et al. Inert gas single-breath washout and structural alteration of respiratory bronchioles. Am Rev Respir Dis 1992; 146: 1167-1172.

32 Shin HW, Condorelli P, Rose-Gottron CM, et al. Probing the impact of axial diffusion on nitric oxide exchange dynamics with heliox. J Appl Physiol 2004; 97: 874-882.

33 Kerckx Y, Van Muylem A. Axial distribution heterogeneity of nitric oxide airway production in healthy adults. $J$ Appl Physiol 2009; 106: 1832-1839.

34 Kim YH, Park HB, Kim MJ, et al. Fractional exhaled nitric oxide and impulse oscillometry in children with allergic rhinitis. Allergy Asthma Immunol Res 2014; 6: 27-32.

35 Aronsson D, Tufvesson E, Ankerst J, et al. Allergic rhinitis with hyper-responsiveness differ from asthma in degree of peripheral obstruction during metacholine challenge test. Clin Physiol Funct Imaging 2008; 28: 81-85.

36 Karamaoun C, Van Muylem A, Haut B. Modeling of the nitric oxide transport in the human lungs. Front Physiol 2016; 7: 255. 